\title{
General Meeting of the Russian Academy of Sciences
}

\author{
G. N. Konnova
}

\author{
N. D. Zelinsky Institute of Organic Chemistry, Russian Academy of Sciences, \\ 47 Leninsky prosp., 119991 Moscow, Russian Federation \\ E-mail:izvan@ioc.ac.ru
}

\begin{abstract}
The scientific and science-organizational activity of the Russian Academy of Sciences in 2020 is described. The most significant achievements of 2020 are highlighted.

Key words: Russian Academy of Sciences, popularization of science, Gold Medals named after famous scientists, development of space industry.
\end{abstract}

The General Meeting of the Russian Academy of Sciences (RAS) was held on April 21-22, 2021, in the Great Hall of the RAS.

The first-day sessions of the General Meeting were attended by approximately 200 participants present in the Hall, with more than 1000 participants being present online.

In his welcome speech, President of the Russian Academy of Sciences, Academician of the RAS, A. M. Sergeev emphasized that leading positions in the world would belong to countries that possess the highest intellectual potential and have their own knowledge-based industry, capable of quickly transforming the results of fundamental achievements into new technologies and products.

The General Meeting of RAS members was addressed by D. N. Chernyshenko, Deputy Chairman of the Russian Federation Government; V. N. Falkov, Minister of Science and Higher Education of the Russian Federation; L. S. Gumerova, Chairman of the Committee on Science of the Federation Council; S. A. Ryabkov, Deputy Minister of Foreign Affairs of the Russian Federation; and $G$. G. Onishchenko, First Deputy Chairman of the Education and Science Committee of the State Duma of the Russian Federation. The General Meeting of RAS members was attended by D. S. Sekirinskii, Deputy Head of the Presidential Office for Science and Educational Policy of the Russian Federation.

The report of $A$. M. Sergeev entitled "On the Priority Trends of the RAS Activity for Implementation of the State Scientific and Technological Policy in the Russian Federation and on the Most Important Scientific Achievements of Russian Scientists in 2020" was devoted to arrangement of conditions for fundamental and exploratory scientific research, expert provision of the activity of state authorities, and attainment of the goals and implementation of the tasks of strategic development of the country. The Head of the Russian Academy of Sciences also highlighted the key challenges of the innovative development of Russia and possible ways of addressing them.

At the Meeting, the M. V. Lomonosov Big Gold Medal of the Russian Academy of Sciences of 2020 and Gold Medals named after outstanding scientists of 2020 were presented to the awardees.
The M. V. Lomonosov Big Gold Medal was awarded to Academician $S$. P. Novikov for his key role in the revival of modern topology in Russia, solving fundamental problems of topology, theory of nonlinear waves, quantum mechanics, and field theory and to Professor M. D. Willard (US), a foreign member of the RAS, for the discovery of exotic smooth structures on multidimensional spheres and solution of fundamental problems of topology and the theory of dynamical systems. The N. I. Pirogov Big Gold Medal of the RAS was awarded to Academician A. I. Archakov for fundamental and applied research in the field of post-genomic technologies, nanobiotechnologies, and proteomics and to Doctor of Medicine Professor M. Marcus (Austria), a foreign Member of the RAS, for fundamental and applied research in the field of clinical pharmacology. N. S. Kurnakov Big Gold Medal was awarded to Academician of the RAS Yu. A. Zolotov for the series of studies "Development of General Methodology for Analytical Chemistry".

Academician S. P. Novikov presented a report entitled "Topology in Theoretical Physics".

The activity of the Presidium of the RAS in the reported period was addressed in the report of Academician N.K. Dolgushkin, Chief Academic Secretary of the Presidium of the RAS.

The reports describing the work of Regional Divisions of the RAS in 2020 were presented by Chairmans of the Regional Divisions of the RAS.

The scientific session "The Contribution of Fundamental Science to the Development of the Space Industry", dedicated to the 60th anniversary of Yuri Gagarin's space flight, took place on April 22, 2021. The scientific session was attended by more than 1230 scientists. D. O. Rogozin, Director General of Roscosmos, State Corporation for Space Activities, and 50 staff members participated in the session. The participants were presented with nine scientific reports and one coreport. Listening to the reports was followed by their discussion and by discussion of the draft resolution of the scientific session.

Received April 28, 2021 accepted May 12, 2021

Published in Russian in Izvestiya Akademii Nauk. Seriya Khimicheskaya, No. 8, p. 1629, August, 2021.

1066-5285/21/7008-1629 (C) 2021 Springer Science+Business Media LLC 